\title{
Indigenous inequities in the presentation and management of stomach cancer in New Zealand: a country with universal health care coverage
}

\author{
Virginia Signal · Diana Sarfati $\cdot$ Ruth Cunningham • \\ Jason Gurney $\cdot$ Jonathon Koea $\cdot$ Lis Ellison-Loschmann
}

Received: 13 January 2014/ Accepted: 22 July 2014/Published online: 7 August 2014

(c) The International Gastric Cancer Association and The Japanese Gastric Cancer Association 2014

\begin{abstract}
Background Māori in New Zealand have markedly higher incidence and poorer survival from stomach cancer than non-Māori. We investigated the presentation, management and survival of stomach cancer in a cohort of newly diagnosed Māori and non-Māori patients.

Methods A clinical notes review of all Māori from the North Island diagnosed between 2006 and 2008, and a random equivalent sample of non-Māori, was conducted (final cohort $n=335$ ). Patient characteristics, tumour characteristics, receipt and timing of treatment and cancerspecific survival were compared.

Results Compared to non-Māori, Māori patients had a younger average age at diagnosis, higher prevalence of congestive heart failure and renal disease, and were more likely to be diagnosed with distal disease (43\% Māori, $26 \%$ non-Māori, $p=0.004)$. Stage and grade distributions were similar between ethnic groups. Two-thirds (66\%) of stage I-III patients had definitive surgery, with similar rates for Māori $(71 \%)$ and non-Māori (68 \%). Māori were less likely to have surgery performed by a specialist upper gastrointestinal surgeon (38 \% Māori, 79 \% non-Māori, $p<0.01)$ and less likely to be treated in a main centre
\end{abstract}

V. Signal $(\bowtie) \cdot$ D. Sarfati · R. Cunningham · J. Gurney Department of Public Health, University of Otago, 23a Mein Street, Newtown, Wellington, New Zealand e-mail: virginia.signal@otago.ac.nz

J. Koea

Department of General Surgery, Waitemata District Health Board, Auckland, New Zealand

L. Ellison-Loschmann

Centre for Public Health Research, Massey University,

Wellington, New Zealand
(44 \% Māori, 87 \% non-Māori, $p<0.01$ ). After adjusting for age, sex, stage, tumour site and comorbidity, Māori had nonsignificant $27 \%$ poorer survival (hazard ratio 1.27, $95 \%$ CI 0.96-1.68).

Conclusions There was evidence of differential presentation and access to specialised surgical services, as well as differential survival, for Māori stomach cancer patients compared to non-Māori. These findings support the development of the national stomach cancer treatment standards and highlight the need for an equity focus within these guidelines.

Keywords Indigenous - Inequity · Stomach · Cancer . Health care quality $\cdot$ Survival

\section{Introduction}

Stomach cancer is a leading cause of mortality worldwide, accounting for some 650,000 deaths annually [1]. In New Zealand, stomach cancer is a particularly important disease for the indigenous Māori population. It was the fourth most frequently diagnosed cancer among Māori males and seventh among Māori females from 1996 to 2001 [2]. In addition, significant inequities in stomach cancer incidence and mortality have been observed between Māori and nonMāori [3]. Throughout the late 1990s, stomach cancer registration rates for Māori were up to five times those of non-Māori, with similar inequities observed in terms of mortality [4-7]. In line with international trends [1], stomach cancer rates for both Māori and non-Māori fell between 1981 and 2004 [3]; however, ethnic inequities remain [3].

Stomach cancer has a poor prognosis $[8,9]$. The 5-year survival for patients with stomach cancer in New Zealand 
is $20 \%$, compared to a 5-year survival of $60 \%$ for all cancer sites combined [8]. Māori have $25 \%$ poorer survival (age adjusted) than non-Māori once diagnosed [10] and have poorer survival regardless of stage at diagnosis [2].

A number of factors make the management of stomach cancer particularly complex. The last 2 decades have seen considerable changes in both the epidemiology and treatment of stomach cancer internationally [9, 11-16]. Increasing obesity and associated gastroesophageal reflux is increasing the proportion of patients diagnosed with tumours located in the proximal stomach, especially for white males in developed countries [1]. Infection with Helicobacter pylori (H. pylori) has a known strong association with the development of distally located stomach cancer and is in turn associated with poverty and overcrowding, particularly that experienced in childhood [1, 17]. Other risk factors include tobacco use and heavy alcohol consumption [3, 15, 16, 18]; therefore, many patients have significant levels of comorbidity at diagnosis [11]. Early stomach cancer is often asymptomatic [18] or the symptoms are common and non-specific [16, 18]; thus, many patients are diagnosed at an advanced stage [11, 14, 16]. The primary treatment modality for stomach cancersurgery-is often complex and can be demanding on the patient, technically challenging for the clinician and considerably resource-intensive to the health care system [9, 14, 16, 19]. As a result of these factors, patients diagnosed with stomach cancer have diverse and complex clinical needs [16], which necessitate care from many different professional groups $[11,16]$. As of 2013, there have been no New Zealand guidelines to inform and standardise clinical practice.

For these reasons, the examination of stomach cancer management in New Zealand is important. New Zealand has a publicly funded national health system that provides specialist and hospital care to all residents without patient charges. Despite this, evidence suggests that much of the ethnic cancer survival inequity observed in New Zealand is due to differential access to, and through, services across the cancer control continuum [20, 21]. Therefore, we investigated the presentation, management and survival of stomach cancer in a cohort of newly diagnosed Māori and non-Māori New Zealanders.

\section{Methods}

Incident cases of stomach cancer diagnosed between 1 January 2006 and 31 December 2008 were identified from the New Zealand Cancer Register (NZCR). Study inclusion criteria were age 25 years or over, no previous diagnosis of stomach cancer and diagnosis with adenocarcinoma (ICD-
10-AM: C1 6.0-16.6, 16.8, 16.9) prior to death. New Zealand comprises two main islands; because around $90 \%$ of Māori are normally resident in the North Island of New Zealand [22], the notes review was limited to this area. All eligible Māori patients, along with a randomly sampled equal number of eligible non-Māori patients, were included. Ethnicity was classified on the basis of NZCR data, where patients are classified as Māori if they have selfidentified as Māori on any previous health record. All other patients were classified as non-Māori (see Appendix for progression of exclusions).

Clinical data were extracted from patients' medical records by an oncology nurse (VS) from public and private hospitals, and where necessary from records held by physicians practicing in private. Data were linked via unique patient identifiers (NHIs) to data collections held in cancer centres, as well as the national administrative hospitalisation dataset (National Minimum Dataset). Data from patients' medical records were recorded on a standardised pro-forma, double-entered into an electronic database, validation checks carried out and discrepancies resolved.

Data collected included: details of patients' presentation and diagnosis; tumour characteristics (tumour grade, site and stage at diagnosis); offer, receipt and timing of treatment (surgical and oncological); details of surgical treatment (type and place of surgery, type of surgeon and postoperative complications within 30 days); and palliative care (referral and receipt). Cancer stage was classified according to the TNM classification system [23]. Data were also collected on a specified list of comorbid conditions present at the time of diagnosis as well as any other significant comorbid condition identified. The 12 most common comorbid conditions in this study were included in the analysis. Comorbidities were analysed as both individual conditions and a categorised 'count' to assess the overall burden of comorbidity at diagnosis.

When describing the place of surgery, hospitals were categorised into main centres, smaller centres or private hospitals [24]. The type of surgeon was defined according to surgeon self-identification in clinic letters or hospital notes. If specialist status was not clear, this was confirmed with District Health Board records. First intervention was defined as the earliest of radiotherapy, chemotherapy, definitive surgery or another surgical intervention such as abdominal paracentesis, gastric or oesophageal stent, or feeding tube insertion. For analysing receipt and timing of definitive surgery and curative chemotherapy, stage IV and the five unstaged patients were excluded.

Age- and sex-standardised rates were calculated by direct standardisation, using the total New Zealand cancer population (2006-2008) as standard. $p$ values were calculated on crude data from Cochrane-Mantel-Haenszel chisquared tests stratified by age group or by $t$ test in the case 
of mean age at diagnosis. Survey methods were used to calculate population estimates for the total New Zealand stomach cancer cohort over the time frame of the study. The final Māori and non-Māori samples were weighted to the total eligible Māori and non-Māori stomach cancer populations. Median times between key steps in the treatment pathway were calculated for the total population and for Māori and non-Māori cohorts. Findings were not corrected for multiple testing.

Cox proportional hazards regression models adjusted for age (continuous), sex, stage (I-IV and unstaged), tumour site (proximal, distal, both proximal and distal, other and missing) and comorbidity count (continuous, 0-12) were used to compare mortality hazard ratios (HRs). Patients who died from other causes and those who did not die were censored at date of death or 31 December 2010 respectively. All analyses were performed using SAS version 9.3. This study was given ethical approval by the MultiRegional Ethics Committee (ref. no. MEC 10/042/EXP).

\section{Results}

The NZCR had a total of 1,115 registrations for stomach cancer (ICD codes C1 6.0-16.6, 16.8, 16.9) nationally during the study period, of which 210 were Māori and 893 non-Māori. Twelve patients had missing ethnicity data and were included in the non-Māori cohort, while 278 patients (16 Māori and 262 non-Māori) were excluded as they resided in the South Island. After all exclusion criteria had been applied, there was a final cohort of 335 patients (172 Māori and 163 non-Māori).

\section{Cohort and disease characteristics}

Table 1 shows the characteristics of the final study cohort. The average age of Māori patients at diagnosis was 10 years younger than non-Māori. Among female patients, this ethnic difference was greater still (female mean age at diagnosis: Māori 57 years, non-Māori 70 years). Nearly half $(46 \%)$ of all patients were diagnosed at stage IV with no difference in the overall distribution of tumour stage between Māori and non-Māori patients ( $p=0.31)$. Māori appeared less likely to have a poorly differentiated cancer, although when missing grade data were removed there was little difference between Māori and non-Māori in this measure (71 \% Māori poorly differentiated compared to $72 \%$ non-Māori).

There were significant differences in the distribution of tumour site between Māori and non-Māori patients; compared with non-Māori, Māori had a higher proportion of distal stomach cancers and a lower proportion of proximal and oesophageal-gastric junction stomach cancers (Table 1). This differential distribution remained when the missing site data were removed (age- and sexstandardised rates for distal tumour site: $58 \%$ Māori, $40 \%$ non-Māori). We observed that the highest proportion of distal tumours occurred in Māori women (agestandardised rates of tumour location: Māori females $54 \%$, Māori males $31 \%$, non-Māori females $29 \%$, nonMāori males $19 \%$ ), while the highest proportion of proximal tumours occurred in non-Māori males (nonMāori males $42 \%$, Māori males $36 \%$, non-Māori females $28 \%$, Māori females $16 \%$ ).

\section{Patient management}

There were no significant ethnic differences in receipt of diagnostic or staging procedures, with most receiving gastroscopy ( $n=319)$ and/or computerised tomography (CT) scan $(n=300)$. Only four received an endoscopic ultrasound.

Of the 172 patients with stage I-III disease, two-thirds had definitive surgery (Table 2). Māori and non-Māori patients had similar rates of definitive surgery; however, when compared with non-Māori patients, Māori were considerably less likely to have surgery performed by a specialist upper gastrointestinal surgeon (38 \% for Māori and $79 \%$ non-Māori patients, $p<0.01)$ and less likely to have surgery in a main centre (44\% for Māori and $87 \%$ non-Māori patients, $p<0.01)$. Even when stratified by surgery type Māori remained less likely than non-Māori to have surgery performed by a specialist surgeon or to be treated in a main centre. Overall, few patients had surgery in a private facility.

Of the patients with stage I-III disease, $49 \%$ were referred to medical oncology; however, few patients received chemotherapy in conjunction with surgery (Table 2). Overall, the median waiting time from date of diagnosis till first intervention was 31 days, till definitive surgery 35 days and till referral to medical oncology 25 days. There were no statistically significant differences in waiting times to treatment between Māori and nonMāori patients. Māori (88 \%) and non-Māori (83\%) stage IV patients were similarly likely to be referred to a palliative service (palliative chemotherapy, palliative radiotherapy or other palliative care).

A substantial proportion of patients with stage I-III disease appeared to have no treatment at all (19\% of stage I-III patients). Upon investigation, this group were older (mean age 79 years) than the stage I-III patients that did have treatment (mean age 63 years) and were more likely to have a higher number of comorbid conditions at diagnosis (mean comorbidity count of 3.06 versus a mean comorbidity count of 1.55 for those stage I-III patients that did have treatment). 
Table 1 Characteristics of all study-eligible patients (stage I-IV)

\begin{tabular}{|c|c|c|c|c|c|c|c|c|c|c|c|}
\hline & \multicolumn{2}{|l|}{ Total } & \multicolumn{4}{|l|}{ Māori } & \multicolumn{4}{|l|}{ Non-Māori } & \multirow[t]{2}{*}{$p$ value } \\
\hline & $n$ & $\%^{\mathrm{a}}$ & $n$ & $\%^{\mathrm{b}}$ & $\%^{\mathrm{c}}$ & $95 \% \mathrm{CI}^{\mathrm{d}}$ & $n$ & $\%^{\mathrm{b}}$ & $\%^{\mathrm{c}}$ & $95 \% \mathrm{CI}^{\mathrm{d}}$ & \\
\hline Total & 335 & & 172 & & & & 163 & & & & \\
\hline \multicolumn{12}{|l|}{ Sex } \\
\hline Male & 197 & 62 & 91 & 53 & - & - & 106 & 65 & - & - & \\
\hline Female & 138 & 38 & 81 & 47 & - & - & 57 & 35 & - & - & 0.11 \\
\hline \multicolumn{12}{|l|}{ Age (years) } \\
\hline $25-49$ & 64 & 16 & 44 & 26 & - & - & 20 & 12 & - & - & \\
\hline $50-64$ & 87 & 22 & 58 & 34 & - & - & 29 & 18 & - & - & \\
\hline $65-74$ & 91 & 28 & 44 & 26 & - & - & 47 & 29 & - & - & \\
\hline$>75$ & 93 & 35 & 26 & 15 & - & - & 67 & 41 & - & - & \\
\hline \multicolumn{12}{|l|}{ Age (characteristics) } \\
\hline Mean age at diagnosis (SD) & $64.9(15.4)$ & & $60.0(14.9)$ & & & & $70.0(14.4)$ & & & & $<0.01$ \\
\hline Age range & $26-101$ & & $26-91$ & & & & 26-101 & & & & \\
\hline \multicolumn{12}{|l|}{ Tumour grade } \\
\hline Well differentiated & 12 & 5 & 3 & 2 & 2 & -0.3 to 3.8 & 9 & 6 & 4 & 1.4 to 6.6 & \\
\hline Moderately differentiated & 43 & 13 & 20 & 12 & 14 & 7.8 to 20.0 & 23 & 14 & 11 & 6.6 to 14.9 & \\
\hline Poorly differentiated & 134 & 42 & 64 & 37 & 36 & 28.2 to 43.9 & 70 & 43 & 48 & 40.6 to 56.3 & \\
\hline Missing & 146 & 40 & 85 & 49 & 48 & 40.1 to 56.3 & 61 & 37 & 37 & 28.9 to 44.4 & 0.14 \\
\hline \multicolumn{12}{|l|}{ Tumour sites } \\
\hline Proximal & 107 & 35 & 44 & 26 & 25 & 18.4 to 31.5 & 63 & 39 & 34 & 26.7 to 41.9 & \\
\hline Distal & 103 & 26 & 69 & 40 & 43 & 35.2 to 50.2 & 34 & 21 & 26 & 18.3 to 34.2 & \\
\hline Proximal and distal & 5 & 1 & 3 & 2 & 2 & -0.2 to 3.2 & 2 & 1 & 2 & -0.8 to 4.8 & \\
\hline Other description & 11 & 2 & 9 & 5 & 5 & 1.6 to 7.4 & 2 & 1 & 1 & -0.4 to 2.4 & \\
\hline Missing & 109 & 35 & 47 & 27 & 26 & 19.5 to 33.0 & 62 & 38 & 36 & 28.1 to 44.7 & 0.004 \\
\hline \multicolumn{12}{|l|}{ Stage } \\
\hline Stage I & 55 & 17 & 25 & 15 & 15 & 9.1 to 21.4 & 30 & 18 & 15 & 10.0 to 20.7 & \\
\hline Stage II & 58 & 16 & 35 & 20 & 23 & 15.5 to 29.4 & 23 & 14 & 14 & 8.0 to 20.9 & \\
\hline Stage III & 59 & 19 & 27 & 16 & 15 & 9.8 to 20.5 & 32 & 20 & 20 & 12.7 to 26.6 & \\
\hline Stage IV & 158 & 46 & 85 & 49 & 47 & 39.2 to 54.9 & 73 & 45 & 49 & 39.9 to 57.2 & \\
\hline Unknown & 5 & 2 & 0 & 0 & 0 & - & 5 & 3 & 2 & 0.3 to 3.7 & 0.31 \\
\hline \multicolumn{12}{|l|}{ Comorbid conditions (count) ${ }^{\mathrm{e}}$} \\
\hline 0 & 108 & 30 & 64 & 37 & 30 & 24.4 to 34.7 & 44 & 27 & 34 & 26.7 to 41.9 & \\
\hline 1 & 79 & 25 & 37 & 22 & 21 & 14.7 to 27.7 & 42 & 26 & 24 & 17.4 to 31.5 & \\
\hline 2 & 67 & 22 & 27 & 16 & 18 & 11.5 to 24.6 & 40 & 25 & 24 & 16.5 to 31.4 & \\
\hline 3 & 42 & 13 & 21 & 12 & 14 & 8.0 to 19.8 & 21 & 13 & 10 & 5.9 to 13.7 & \\
\hline $4+$ & 39 & 11 & 23 & 13 & 17 & 10.7 to 23.9 & 16 & 10 & 7 & 3.9 to 10.9 & 0.11 \\
\hline \multicolumn{12}{|c|}{ Comorbid conditions (individual) ${ }^{\mathrm{e}}$} \\
\hline Angina & 52 & 16 & 25 & 15 & 18 & 11.3 to 24.5 & 27 & 17 & 12 & 7.9 to 16.3 & 0.31 \\
\hline Hypertension & 133 & 41 & 64 & 37 & 43 & 34.9 to 50.3 & 69 & 42 & 39 & 31.2 to 47.3 & 0.33 \\
\hline Myocardial infarction & 29 & 10 & 12 & 7 & 9 & 3.5 to 13.5 & 17 & 10 & 8 & 4.2 to 11.2 & 0.97 \\
\hline Arrhythmia & 54 & 17 & 25 & 15 & 20 & 13.8 to 26.8 & 29 & 18 & 17 & 10.3 to 22.7 & 0.76 \\
\hline Mild CPD & 22 & 7 & 11 & 6 & 8 & 2.5 to 11.3 & 11 & 7 & 7 & 2.2 to 11.0 & 0.83 \\
\hline Moderate/severe CPD & 27 & 9 & 10 & 6 & 7 & 3.1 to 13.5 & 17 & 10 & 8 & 4.2 to 10.9 & 0.69 \\
\hline Congestive heart failure & 29 & 8 & 18 & 10 & 14 & 8.0 to 20.4 & 11 & 7 & 5 & 2.3 to 8.2 & 0.003 \\
\hline CVA & 38 & 13 & 13 & 8 & 9 & 4.2 to 14.2 & 25 & 15 & 11 & 7.4 to 15.6 & 0.49 \\
\hline Obesity & 21 & 5 & 14 & 8 & 8 & 3.9 to 11.2 & 7 & 4 & 4 & 0.8 to 7.6 & 0.26 \\
\hline Diabetes & 70 & 19 & 42 & 24 & 26 & 18.5 to 33.7 & 28 & 17 & 15 & 9.8 to 20.7 & 0.09 \\
\hline
\end{tabular}


Table 1 continued

\begin{tabular}{|c|c|c|c|c|c|c|c|c|c|c|c|}
\hline & \multicolumn{2}{|c|}{ Total } & \multicolumn{4}{|c|}{ Māori } & \multicolumn{4}{|c|}{ Non-Māori } & \multirow[t]{2}{*}{$p$ value } \\
\hline & $n$ & $\%^{a}$ & $n$ & $\%^{\mathrm{b}}$ & $\%^{\mathrm{c}}$ & $95 \% \mathrm{CI}^{\mathrm{d}}$ & $n$ & $\%^{\mathrm{b}}$ & $\%^{\mathrm{c}}$ & $95 \% \mathrm{CI}^{\mathrm{d}}$ & \\
\hline Other primary cancer & 29 & 9 & 13 & 8 & 9 & 3.8 to 13.6 & 16 & 10 & 9 & 4.3 to 14.0 & 0.83 \\
\hline Renal disease & 22 & 5 & 17 & 10 & 11 & 5.6 to 16.1 & 5 & 3 & 3 & 0.3 to 4.7 & 0.005 \\
\hline
\end{tabular}

$n$ number, $C P D$ chronic pulmonary disease, $C V A$ cerebrovascular accident

${ }^{\text {a }}$ Population estimates

${ }^{\mathrm{b}}$ Crude estimates, based on the actual study sample

c Age and sex standardised estimates

d The $95 \%$ confidence intervals provided for age and sex standardised estimates

e Twelve most common comorbid conditions in this study

Māori appeared to have poorer cancer-specific survival than non-Māori. After adjusting for age, sex, stage, tumour site and comorbidity, Māori patients were $27 \%$ more likely to die of their stomach cancer than non-Māori although the difference was not statistically significant (HR $1.27,95 \%$ CI $0.96-1.68)$.

\section{Discussion}

This study found both similarities and differences in the presentation, management and survival of stomach cancer for Māori when compared with non-Māori patients in New Zealand. While there were no significant differences in cancer grade or stage at diagnosis, Māori were younger and presented with a much higher proportion of distal stomach cancers when compared with non-Māori patients. Māori had significantly higher prevalence of comorbid congestive heart failure and renal disease. Of those patients diagnosed with stage I-III disease, Māori were equally likely to receive definitive surgery as non-Māori, although Māori were less likely to have surgery performed by a specialist upper gastrointestinal surgeon and less likely to be treated in a main centre. Few patients overall received chemotherapy. Māori in this cohort appeared less likely to survive once diagnosed with stomach cancer, although the study was underpowered to statistically confirm a $27 \%$ excess mortality among Māori patients.

Our observation of a higher proportion of distal cancer for Māori is in keeping with previous New Zealand-based studies $[25,26]$. This finding suggests that there may be differing aetiological factors driving the high incidence rates of stomach cancer observed for Māori. Infection with $H$. pylori and smoking have both been shown to be more likely to lead to the development of distal stomach cancer over proximal $[1,9,25,27-29]$. The high proportion of distal stomach cancer among Māori women when compared with non-Māori women may be related to their higher rates of $H$. pylori in combination with a very high smoking prevalence and younger age at initiation [25, 3032]. Māori women have one of the highest rates of smoking in the world, more than Māori men and over twice that of non-Māori women [30]. These two factors are thought to interact to increase the risk of stomach cancer more than would be expected given each risk factor alone [29, 33]. Further research into the risk factors of stomach cancer for Māori, and whether there are significant gender differences as suggested by this study, is warranted. These findings add weight to a continued emphasis on reducing smoking as well as the development of interventions to prevent the transmission of (and to treat) $H$. pylori, particularly among Māori.

Our observation that Māori were more likely to have comorbidities is consistent with previous studies that have found Māori patients to have higher rates of comorbidity than non-Māori patients with cancer [34]. Comorbidity is known to impact on the quality of care received by patients and on the likelihood of survival from cancer [34-37]. The fact that the group of stage I-III patients in this study who did not receive any treatment had higher levels of comorbidity than those who did receive treatment suggests that comorbidity is playing a role in the decision to treat. The effect of comorbidity on treatment and subsequent survival requires further investigation.

Surgery was the primary treatment modality over our study period, which is consistent with international guidelines in use at the time [12, 14, 19]. However, our findings suggest that the guideline recommendations were not being met, particularly for Māori patients. International guidelines, published in 2002 and 2006, recommended that all patients should have treatment planned within the multidisciplinary context and that at all stages of disease surgery should be undertaken by experienced surgeons in high-volume specialised units $[14,19]$ with appropriate postoperative care available [14]. Māori in this study were more likely to have distal disease and thus more likely to undergo less complex partial gastrectomy. They were also, however, less likely than non-Māori to 
Table 2 Characteristics of definitive surgery for stage I-III patients

\begin{tabular}{|c|c|c|c|c|c|c|c|c|c|c|c|}
\hline & \multicolumn{2}{|c|}{ Total } & \multicolumn{4}{|c|}{ Māori } & \multicolumn{4}{|c|}{ Non-Māori } & \multirow[t]{2}{*}{$p$ value } \\
\hline & $n$ & $\%^{\mathrm{a}}$ & $n$ & $\%^{\mathrm{b}}$ & $\%^{\mathrm{c}}$ & $95 \% \mathrm{CI}^{\mathrm{d}}$ & $n$ & $\%^{\mathrm{b}}$ & $\%^{\mathrm{c}}$ & $95 \% \mathrm{CI}^{\mathrm{d}}$ & \\
\hline Definitive surgery & 119 & 66 & 65 & 75 & 71 & 62.1 to 80.4 & 54 & 64 & 68 & 57.4 to 77.8 & 0.79 \\
\hline Total & 172 & & 87 & & & & 85 & & & & \\
\hline \multicolumn{12}{|l|}{ Place of surgery ${ }^{\mathrm{e}}$} \\
\hline Main centre & 76 & 72 & 33 & 51 & 43 & 29.8 to 55.3 & 43 & 80 & 83 & 71.7 to 93.4 & $<0.01$ \\
\hline Smaller centre & 38 & 23 & 30 & 46 & 54 & 41.2 to 67.1 & 8 & 15 & 12 & 3.3 to 20.9 & $<0.001$ \\
\hline \multirow[t]{2}{*}{ Private } & 5 & 5 & 2 & 3 & 3 & -1.0 to 7.6 & 3 & 6 & 5 & -1.2 to 11.9 & 0.54 \\
\hline & 119 & & 65 & & & & 54 & & & & \\
\hline \multicolumn{12}{|l|}{ Type of surgery ${ }^{\mathrm{e}}$} \\
\hline Local excision/EMR & 2 & 2 & 1 & 2 & 1 & -1.0 to 3.4 & 1 & 2 & 1 & -0.8 to 2.5 & \\
\hline Ivor-Lewis oesophagectomy & 9 & 11 & 1 & 2 & 3 & 3.0 to 8.5 & 8 & 15 & 12 & 3.8 to 19.3 & \\
\hline Gastrojejunostomy & 1 & 1 & 0 & 0 & 0 & - & 1 & 2 & 1 & -0.8 to 2.5 & \\
\hline Partial gastrectomy & 56 & 43 & 35 & 54 & 59 & 48.4 to 68.6 & 21 & 39 & 49 & 37.6 to 60.6 & \\
\hline Total gastrectomy & 46 & 39 & 25 & 38 & 34 & 23. 7 to 45.0 & 21 & 39 & 36 & 23.2 to 48.5 & \\
\hline \multirow[t]{2}{*}{ Laparotomy without resection } & 5 & 4 & 3 & 5 & 3 & -0.21 to 5.6 & 2 & 4 & 2 & -0.5 to 3.9 & 0.14 \\
\hline & 119 & & 65 & & & & 54 & & & & \\
\hline \multicolumn{12}{|l|}{ Type of surgeon ${ }^{\mathrm{e}}$} \\
\hline General surgeon & 50 & 34 & 36 & 55 & 62 & 51.6 to 72.6 & 14 & 26 & 21 & 9.7 to 32.3 & \\
\hline \multirow[t]{2}{*}{ Specialist surgeon } & 69 & 66 & 29 & 45 & 38 & 27.3 to 48.4 & 40 & 74 & 79 & 67.7 to 90.3 & $<0.01$ \\
\hline & 119 & & 65 & & & & 54 & & & & \\
\hline \multicolumn{12}{|l|}{ Number of nodes resected ${ }^{\mathrm{f}}$} \\
\hline $0-14$ & 40 & 45 & 20 & 37 & 39 & 29.3 to 48.3 & 20 & 48 & 42 & 29.4 to 54.2 & \\
\hline \multirow[t]{2}{*}{$15+$} & 56 & 55 & 34 & 63 & 61 & 51.2 to 70.7 & 22 & 52 & 58 & 45.8 to 70.6 & 0.5 \\
\hline & 96 & & 54 & & & & 42 & & & & \\
\hline \multicolumn{12}{|l|}{ Postoperative complications $^{\mathrm{g}}$} \\
\hline Any postoperative complication & 70 & 62 & 35 & 54 & 59 & 48.2 to 69.8 & 35 & 65 & 55 & 39.5 to 70.9 & 0.43 \\
\hline Reoperation $^{\mathrm{h}}$ & 13 & 11 & 7 & 11 & 11 & 3.1 to 19.0 & 6 & 11 & 7 & 1.9 to 12.7 & 0.78 \\
\hline Organ failure ${ }^{i}$ & 13 & 12 & 6 & 9 & 9 & 1.6 to 15.8 & 7 & 13 & 8 & 2.3 to 13.2 & 0.65 \\
\hline Pneumonia & 17 & 15 & 8 & 12 & 12 & 3.8 to 20.5 & 9 & 17 & 10 & 4.3 to 16.3 & 0.97 \\
\hline Sepsis & 17 & 15 & 9 & 14 & 13 & 5.5 to 19.6 & 8 & 15 & 15 & 3.6 to 25.9 & 0.93 \\
\hline \multirow[t]{2}{*}{ Death following surgery } & 3 & 3 & 1 & 2 & 1 & -1.0 to 3.5 & 2 & 4 & 2 & -0.8 to 5.1 & 0.8 \\
\hline & 119 & & 65 & & & & 54 & & & & \\
\hline \multicolumn{12}{|l|}{ Chemotherapy $^{\mathrm{j}}$} \\
\hline Pre-operative & 20 & 15 & 13 & 20 & 13 & 6.8 to 18.9 & 7 & 13 & 20 & 5.9 to 33.2 & 0.99 \\
\hline \multirow[t]{2}{*}{ Post-operative } & 31 & 25 & 18 & 28 & 22 & 13.9 to 30.6 & 13 & 24 & 34 & 21.5 to 46.5 & 0.34 \\
\hline & 119 & & 65 & & & & 54 & & & & \\
\hline
\end{tabular}

$n$ number, EMR endoscopic mucosal resection

${ }^{a}$ Weighted

${ }^{b}$ Crude

c Age and sex standardised estimates

d The $95 \%$ confidence intervals provided for age and sex standardised estimates

e Limited to those who received definitive surgery

${ }^{\mathrm{f}}$ Limited to those with data and who received surgery, one of: Ivor-Lewis oesophagectomy, gastrojejunostomy, partial gastrectomy, total gastrectomy

g Limited to those who received definitive surgery

${ }^{\mathrm{h}}$ Reasons for reoperation included anastomotic leakage, bleeding, infarcted bowel or stomach, division of adhesions and intra-abdominal abscess

${ }^{\mathrm{i}}$ Includes cardiac, respiratory and renal failure

${ }^{\mathrm{j}}$ Limited to those who received definitive surgery and curative chemotherapy 
have a specialist upper gastrointestinal surgeon or to have surgery performed in a main centre with specialist postoperative support whether their operation was a partial gastrectomy or the more complex total gastrectomy. While this may in part be due to more Māori living in minor urban [22] and rural areas [38], these findings indicate differential access to specialised surgical stomach cancer services for Māori.

The only current guideline related to stomach cancer in New Zealand during the time frames of this study ('Suspected cancer in primary care') [39] advises primary care practitioners to consider stomach cancer at a younger age (suggesting 10 years earlier) when treating Māori patients compared to the general population. This recommendation is supported by the findings of the current study. The differential average age at diagnosis is likely due to the younger age structure of the Māori population [22], but also may indicate a true younger age at onset possibly due to a higher prevalence of known risk factors among Māori $[25,30-32]$.

International stomach cancer treatment guidelines have changed over the last decade, particularly in the area of medical oncology. In 2002, the UK guideline recommended that chemotherapy is 'not standard practice' but is given in the context of clinical trials only [14]. By 2011 the updated UK guideline advised clinicians that neoadjuvant (before surgery) and adjuvant (after surgery) chemotherapy 'conveys a significant survival benefit' and recommended that patients be given adjuvant treatment if neoadjuvant has been missed [15]. Despite increasing evidence during the time frames of this study that medical oncology is an effective treatment modality for stomach cancer, little chemotherapy was given in this study. A New Zealand study published in 2002 [9] found that few patients with stomach cancer received multimodality therapy despite changing evidence at the time to support such treatment. The authors also highlighted the evidence for better staging and treatment planning offered by endoscopic ultrasonography in conjunction with CT scanning [9]. Their study, using data collected between 1995 and 1997, found that $10 \%$ of patients receiving an operation for a gastro-oesphageal tumour had an unnecessary 'open and close' surgical procedure, indicating the need for better surgical planning information gained by endoscopic ultrasonography prior to surgery. Despite these recommendations, our findings indicate that clinical practice remained unchanged a decade later, with only four patients receiving an endoscopic ultrasound in the study cohort. The absence of New Zealand-based guidelines to inform clinical practice during the time period covered by this study may be significant.
The government has recognised the need for uniform treatment guidelines for stomach cancer and national standards have recently been developed [40].

A key strength of this study is that it is based on a full clinical notes review, which allowed us to collect comprehensive presentation and management data on all eligible patients and conduct a detailed comparison between Māori and non-Māori patients. Importantly, while the NZCR reported 101 patients within this cohort as unstaged, we were able to determine stage at diagnosis for all but five patients and thus include this important treatment and prognostic factor in our analysis. We were however unable to obtain complete data on the key tumour variables of grade and site or on patient smoking status. Firm conclusions are limited by our small sample size, especially considering $46 \%$ (those patients stage IV at diagnosis) were excluded from some analyses. Additionally, data on histological subtype (diffuse or intestinal) were not collected. Māori have been shown to be more likely to present with diffuse stomach cancer, which is thought to negatively impact on prognosis $[17,25]$. Finally, it is not possible to rule out the possibility of chance findings, particularly given the number of comparisons. However, the key statistically significant findings (such as Māori having higher levels of comorbidity, more distal cancers and less access to specialised care) are those where we had a priori expectation of finding differences; reducing the possibility that these are chance findings.

\section{Conclusion}

The investigation of stomach cancer and its management is a high priority for Māori cancer control. We found evidence of differential presentation, especially tumour site, and in access to specialised surgical services for Māori stomach cancer patients compared to non-Māori. Māori also appear $27 \%$ less likely to survive once diagnosed. These findings support the development and implementation of national stomach cancer treatment standards for New Zealand. They also highlight the imperative that these standards have an equity focus and prioritise the needs of Māori.

Acknowledgments This study is part of a larger study, 'C3: Cancer Care and Comorbidity', which is funded by the Health Research Council of New Zealand. It was completed as part of a PhD thesis within the Cancer Control and Screening Research Group, University of Otago, Wellington, New Zealand.

Conflict of interest None. 


\section{Appendix: Progression of exclusions}

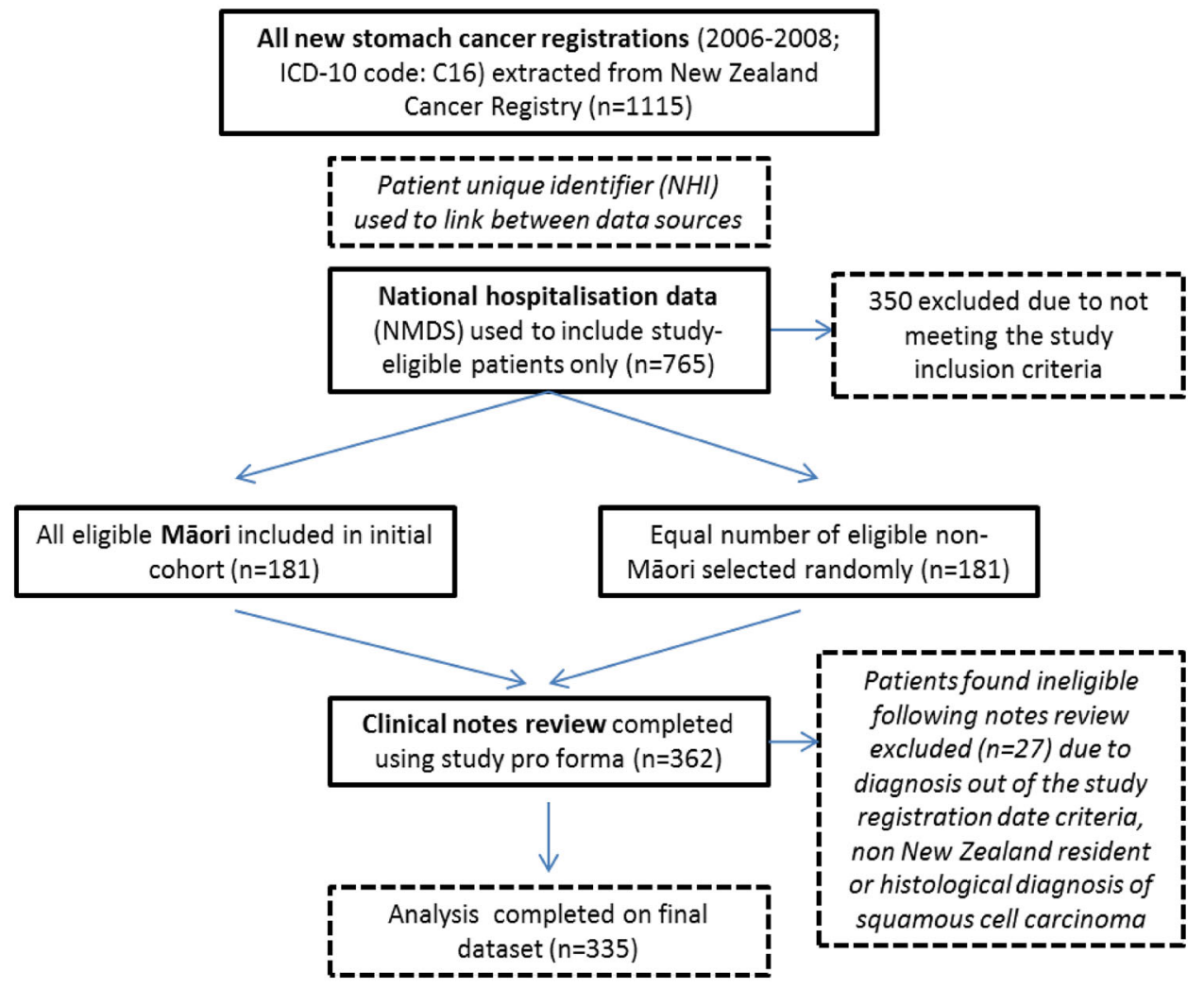

\section{References}

1. Crew KD, Neugut AI. Epidemiology of gastric cancer. World J Gastroenterol. 2006;12(3):354-62.

2. Robson B, Purdie G, Cormack D. Unequal impact: Māori and non-Māori cancer statistics 1996-2001. Wellington: Ministry of Health; 2006.

3. Blakely T, Shaw C, Atkinson J. Cancer trends: trends in incidence by ethnic and socioeconomic group, New Zealand 1981-2004. Wellington: Ministry of Health; 2010.

4. New Zealand Health Information Service. Cancer: new registrations and deaths 2009. Wellington: Ministry of Health; 2012.

5. New Zealand Health Information Service. Cancer: new registrations and deaths 2004. Wellington: Ministry of Health; 2007.

6. New Zealand Health Information Service. Cancer: new registrations and deaths 2008. Wellington: Ministry of Health; 2011.

7. New Zealand Health Information Service. Cancer: new registrations and deaths 2006. Wellington: Ministry of Health; 2010.

8. New Zealand Health Information Service. Cancer patient survival: covering the period 1994 to 2003. Wellington: Ministry of Health; 2006.

9. Martin IG. Gastro-oesophageal malignancy in New Zealand: 1995-97. N Z Med J. 2002;115(1148):64-7.

10. Soeberg $M$, et al. Cancer trends: trends in cancer survival by ethnic and socioeconomic group, New Zealand 1991-2004. Wellington: Univ of Otago and Ministry of Health; 2012.

11. Palser TR, et al. Re-organisation of oesophago-gastric cancer care in England: progress and remaining challenges. BMC Health Serv Res. 2009; 9(204).
12. Okines A, et al. Gastric cancer: ESMO clinical practice guidelines for diagnosis, treatment and follow-up. Ann Oncol. 2010;21:vi50-4.

13. Nakajima T. Gastric cancer treatment guidelines in Japan. Gastric Cancer. 2002;5(1):1-5.

14. Allum WH, et al. Guidelines for the management of oesophageal and gastric cancer. Gut. 2002;50(Suppl 5):v1-23.

15. Allum WH, et al. Guidelines for the management of oesophageal and gastric cancer. Gut. 2011;60(11):1449-72.

16. NHS Executive. Guidance on commissioning cancer services: improving outcomes in upper gastro-intestinal cancers. London: NHS Executive; 2001.

17. Blair V, Kahokehr A, Sammour T. Cancer in Maori: lessons from prostate, colorectal and gastric cancer and progress in hereditary stomach cancer in New Zealand. ANZ J of Surg. 2012;83:42-8.

18. Layke JC, Lopez PP. Gastric cancer: diagnosis and treatment options. Am Fam Phys. 2004;69(5):1133-40.

19. National Health Service. The management of oesophageal and gastric cancer. Edinburgh: Scottish Intercollegiate Guidelines Network; 2006.

20. Cormack D, et al. Access to cancer services for Māori. Wellington: University of Otago; 2005.

21. Jefferys M, et al. Ethnic in equalities in cancer survival in New Zealand: linkage study. Am J Pub Health. 2005;95(5):834-7.

22. Robson B, Harris R. Hauora: Màori Standards of Health IV. A study of the years 2000-2005. Wellington: Te Ròpù Rangahau Hauora a Eru Pòmare; 2007.

23. Edge SB, et al. In: AJCC (ed.). AJCC Cancer Staging Manual. 7th ed. New York: Springer-Verlag; 2010. 
24. Hill S, et al. Ethnicity and management of colon cancer in New Zealand: do indigenous patients get a worse deal? Cancer. 2010;116:3205-14.

25. Biggar M, et al. Gastric cancer location and histological subtype in Pacific people and Māori defies international trends. N Z Med J. 2011;124:39-44.

26. Armstrong RW, Borman B. Trends in incidence rates of adenocarcinoma of the oesophagus and gastric cardia in New Zealand, 1978-1992. Int J Epidemiol. 1996;25(5):941-7.

27. McLoughlin JM. Adenocarcinoma of the stomach: a review. BUMC Proc. 2004;17:391-9.

28. Kamangar F, et al. Opposing risks of gastric cardia and noncardia gastric adenocarcinomas associated with helicobacter pylori seropositivity. J Natl Cancer Inst. 2006;98(20):1445-52.

29. Forman D, Burley VJ. Gastric cancer: global pattern of the disease and an overview of environmental risk factors. Best Pract Res Clin Gastroenterol. 2006;20(4):633-49.

30. The Quit Group and the Ministry of Health. Māori smoking and tobacco use 2009. Wellington: Ministry of Health; 2009.

31. Ministry of Health. A portrait of health: key results of the 2006/07 New Zealand health survey. Wellington: Ministry of Health; 2008.

32. Fraser AG, et al. Prevalence of Helicobacter pylori infection in different ethnic groups in New Zealand children and adults. Aust N Z J Med. 26(5): 646-51.
33. World Health Organisation. In: Peter, B, Bernard, L editors. World Cancer Report 2008. Lyon: International Agency for Research on Cancer; 2008.

34. Hill S, et al. Survival disparities in Indigenous and non-Indigenous New Zealanders with colon cancer: the role of patient comorbidity, treatment and health service factors. J Epidemiol Community Health. 2010;64(2):117-23.

35. Lemmens VE, et al. Co-morbidity leads to altered treatment and worse survival of elderly patients with colorectal cancer. $\mathrm{Br} \mathbf{J}$ Surg. 2005;92(5):615-23.

36. Gross CP, et al. Multimorbidity and survival in older persons with colorectal cancer. J Am Geriatr Soc. 2006;54(12):1898-904.

37. Sarfati $\mathrm{D}$, et al. The effect of comorbidity on the use of adjuvant chemotherapy and survival from colon cancer: a retrospective cohort study. BMC Cancer. 2009;9(1):116.

38. Robson B, Purdie G, Cormack D. Unequal impact II: Māori and non-Māori cancer statistics by deprivation and rural-urban status, 2002-2006. Wellington: Ministry of Health; 2010.

39. New Zealand Guidelines Group. Suspected cancer in primary care: guidelines for investigation, referral and reducing ethnic disparities. Wellington: Ministry of Health; 2009.

40. National HBP/Upper GI Tumour Standards Working Group. Standards of service provision for upper gastrointestinal cancer patients in New Zealand-provisional. Wellington: Ministry of Health; 2013. 